\title{
Criteria and Indicators for Strategic Urban Forest Planning and Management
}

\author{
W. Andy Kenney, Philip J.E. van Wassenaer, and Alexander L. Satel
}

\begin{abstract}
The success of urban forest management is frequently predicated upon achieving absolute canopy cover targets. This two-dimensional view of the urban forest does not provide a comprehensive assessment of urban forest stewardship in a community and does not account for an area's potential to support a forest canopy. A comprehensive set of performance-based criteria and indicators concerning the community's vegetation resource, community framework and resource management approach is described. This set of broadly based measures provides a more useful tool for the evaluation of urban forest management success and strategic management planning. Key Words. Canopy Cover; Municipal Planning; Relative Canopy Cover; Sustainability; Urban Forest Planning; Urban Forestry.
\end{abstract}

The diverse benefits provided by urban forests are well understood (Dwyer et al. 1991). Recent efforts to quantify the value of ecological services such as heat-island mitigation, $\mathrm{CO}_{2}$ reduction, and stormwater attenuation (McPherson et al. 2005) conclusively demonstrate that trees account for an important part of any community's infrastructure, providing positive returns on investment and tangible benefits to urban residents. Urban forests composed of diverse species and age classes provide a wider range of benefits over the long term, particularly if urban trees are large-growing, long-lived specimens.

Currently in North America, a common way to describe the extent of urban forests is to measure the amount of canopy cover provided by trees. Canopy cover is essentially a two-dimensional measurement of the horizontal surface area of the forest, as seen from a bird's-eye view. As part of the emerging public policy and scientific dialogue on urban forest management, canopy cover goals have received a great deal of attention as a management target. While canopy cover provides a very simple and intuitive measure of the extent of a community's urban forest, a much more effective measure of the success of urban forest stewardship rests with moving steadily and aggressively toward a more comprehensive set of performance indicators.

This paper discusses some limitations to focusing primarily on canopy cover, and builds on the work of Clark et al. (1997) to describe a more comprehensive set of criteria and performance indicators by which to measure urban forest management success. It is important to note that the criteria and indicators-based (C\&I) urban forest management approach described in this paper can be applied by communities of any size, even with the most limited of budgets. While local circumstances differ, urban forests everywhere face similar challenges, from limited community involvement, to invasive species, to inadequate growing spaces, just to name a few. Criteria and indicators provide a standardized set of performance measures that can relate to urban forests any- where and help guide managers to improve the health of their tree resource and the effectiveness of their management approach.

Implementing a criteria and indicators-based approach to assessing the urban forest and its management need not be a time or resource-consuming undertaking. The majority of criteria can be assessed as a simple collaborative desktop exercise, while others require some data, such as tree inventories or GIS-based mapping. Any criterion which cannot be readily assessed-be it due to a lack of available information, inadequate resources, or other reasons - can still serve to highlight opportunities for improvement. As such, it is important that communities utilizing this approach do not simply pick-and-choose certain criteria for assessment, but rather work through the entire set of twenty-five criteria and indicators presented in this paper. The prioritization of each criterion can be addressed through the management planning process.

Finally, it must be noted that use of the C\&I approach is not limited to municipal or other government staff, who are traditionally considered the chief managers of urban forest resources. Rather, a collaborative approach among municipal staff, community and stewardship groups, and other stakeholders will invariably result in more accurate and, oftentimes, higher rankings on the assessment scale.

A need to modify and update the original criteria and indicators developed by Clark et al. (1997) was identified by the authors due to the limited application of the approach to achieving urban forest sustainability. When first published, the paper showed promise by providing objectives that spanned a range of urban forestry issues and enabled managers to focus their efforts and frequently limited budgets. More than a decade later, few urban forest management plans or programs are informed by these criteria and indicators, making the tracking of progress difficult and potentially resulting in missed opportunities and misallocation of resources. By expanding the list of criteria and indicators and modifying others to shift the focus towards more easily quantifi- 
able results, it is hoped that this assessment framework may once again become a leading model to be taken up by urban forest stewards interested in building livable and sustainable communities.

\section{CANOPY COVER}

All too often, urban forest management programs are driven by the need to increase urban forest canopy cover. Setting canopy cover goals has many implications, including the associated need for increased tree planting and the long-term resources required to manage the expanding urban forest. The following discussion on targets for canopy cover provides some context for policy makers and managers, and further justifies the need for a broader approach to urban forest assessment and management.

The advantage of measuring canopy cover is that it is a simple, intuitive indicator of the extent of the urban forest. However, measuring only canopy cover does not provide information about other essential parameters required to effectively manage and sustain a community's urban forest. For example, canopy cover provides no indication of the species diversity of the forest, no measure of the condition of forest resources, and no indication of the age or size class distribution of the trees making up the urban forest. A popular target for urban forest canopy cover recommended by American Forests is $40 \%$ (30\% in arid regions) (American Forests 2009). While ambitious and desirable, for a variety of reasons this figure may be unattainable in many urban centers, and difficult to attain in others. Setting overly ambitious canopy cover targets can unduly focus urban forest management activities on tree planting. This could be to the detriment of other strategic and more comprehensive approaches to management.

Also, canopy cover measurements alone are unable to provide an estimate of the carrying capacity of any particular part of a community. For example, a commercial area may have a canopy cover of $10 \%$, and this may be all that the area can support due to a high proportion of hard surface cover. Another part of the community may be dominated by light industry and also exhibit $10 \%$ canopy cover, but with the potential to support significantly more. Measuring canopy cover alone tells us little of this possible variation and does not reflect potential regional differences (Sanders 1984).

Without a clear understanding of several factors that ultimately determine canopy cover, setting meaningful targets is a significant challenge. There are some factors beyond the control of urban forest managers that may render canopy cover estimates unreliable, including:

- Mortality rates: Little information is available about baseline tree mortality rates in urban forests (Nowak et al. 2004).

- Climate change: The potential impacts of climate change in general, and extreme weather events more specifically, are difficult to predict.

- Invasive insects: The potential impacts of invasive alien insects are difficult to predict but could have significant impacts. For example, Humble and Allen (2004) note that many invasive insects have been detected adjacent to the port of Vancouver, British Columbia, Canada, illustrating that continued vigilance is imperative and that tree mortality rates must be considered with caution.

- In-fill development/intensification: In established residential neighborhoods, in-fill development can be expected to contribute to further losses of mature tree canopy.
- Tree habitat: Uncertainty about the availability and quality of growing space for new trees.

- Land and tree tenure: A high proportion of the urban forest is under private ownership, placing a disproportionate reliance upon landowners to maintain and expand the urban forest.

- Financial considerations: Budgetary and resource implications for the long-term maintenance required to support aggressive tree establishment goals.

Ideally, an assessment of a community's potential canopy cover capacity, such as the USDA Forest Service's Urban Tree Canopy (USDA Forest Service 2010) and Forest Opportunity Spectrum assessment, should be conducted before any meaningful targets are set. Similar methods have also been developed by Kenney (2008), Wua et al. (2008), Kirnbauer et al. (2009), and Monear and Hanou (2010). A high-quality potential canopy cover assessment should not only provide an indication of available plantable spaces, but also take into consideration aboveground growing space for future canopy expansion, current and future land uses, regional climate and soils, and other key variables that may affect tree growth and longevity. While effective tree establishment is important, it is only part of a strategy for sustainable urban forest management. The protection and maintenance of the existing trees that form the community's urban forest canopy is critical. Additionally, the importance of planning for, and adequate funding of, tree maintenance and protection throughout the life of the trees cannot be overstated.

In recognition of the significant limitations of using tree canopy cover as a strategic objective for urban forest management, the study authors suggest an alternative means for setting and achieving management targets through the use of twenty-five criteria and indicators for urban forest sustainability. The concept of canopy cover is included as only one of these criteria.

\section{CRITERIA AND INDICATORS OF URBAN FOREST MANAGEMENT SUCCESS}

The concept of using criteria and indicators as sustainable forest management tools originates from the 1994 meeting of the Working Group on Criteria and Indicators for the Conservation and Sustainable Management of Temperate and Boreal Forests in Geneva, Switzerland, as part of the Montréal Process. Since then, many sets of criteria and indicators of sustainable forest management have been developed around the world. For example, the Canadian Council of Forest Ministers has published Criteria and Indicators of Sustainable Forest Management in Canada: National Status 2005 (Canadian Council of Forest Ministers 2006) to underscore the applicability of the C\&I approach to more traditional production-based forest management planning.

Urban forest managers must be able to clearly identify where specific goals or targets have been met and when adaptations to management approaches appear to be necessary. Assessing successful urban forest management therefore also requires clearly defined targets, or criteria, and specific performance indicators of success. The performance indicators enable measurement of progress towards the achievement of the key objectives for each criterion, which in turn permits the ongoing evaluation of success in implementing the community's urban forest strategy. 
More than a decade ago Clark et al. (1997) proposed a set of tools to reflect the specific issues concerning urban forestry, and provided a list of criteria and indicators for urban forest sustainability that considered:

- the vegetation resource

- the community framework, and

- the resource management approach.

Each criterion includes a key objective and performance indicators describing low, moderate, good, and optimal levels of performance. In a subsequent paper, Clark and Matheny (1998) surveyed a sample of 25 U.S. municipalities and scored their performance in terms of urban forest sustainability using the criteria and indicators matrix. General findings from the survey responses suggested that, on average, communities scored 49 of a maximum 80 points.

In the following pages, the authors of the current study build upon several of the criteria and indicators developed by Clark et al. (1997), and provide more detail in a number of areas to better position C\&I as tools for strategic urban forest management planning.

\section{The Vegetation Resource}

Clark et al. (1997) provided four criteria for success in managing the urban forest vegetation resource: 1) canopy cover, 2) age distribution of trees in the community, 3) species mix, and 4) native vegetation. Suggested here are two additional criteria to be incorporated into strategic urban forest management planning: 5) the condition of publicly owned trees, and 6) publicly owned natural areas. Further proposed is a revision to the original canopy cover criterion.

Clark et al. (1997) suggested that the key objective in managing canopy cover is to achieve a climate-appropriate degree of tree cover within the community, yet the performance indicators presented only track increasing levels of sophistication in assessment or technological input. As such, there is a disconnect between the key objective and the indicators available to urban forest managers to evaluate the success of their management strategies. Suggested here is a revised performance indicator, relative canopy cover, which allows for a quantifiable comparison between actual canopy cover and the maximum potential cover within a community (Appendix 1). In other words:

\section{Relative Canopy Cover $=\quad$ Canopy Cover Potential Canopy Cover}

The application of this criterion is, of course, predicated on the availability of a measure of the carrying capacity or potential canopy cover, as discussed previously.

In terms of tree age distribution, the original key objective was to build to provide for an uneven age distribution city-wide and at the neighborhood level. The initial indicators proposed by Clark et al. (1997) focused on the methods of assessing tree age distribution, but did not provide actual age class targets at different performance levels. The revised indicators introduce the concept of relative diameter (RDBH) as a more meaningful target. $\mathrm{RDBH}$ is the ratio between a tree's measured diameter at breast height and the maximum diameter for its species. Species specific maximum DBH values can be derived from the literature and/ or local experience. For example, in southern Ontario, Canada, a database has been developed based on maximum $\mathrm{DBH}$ values from Farrar (1995), Kershaw (2001), Lauriault (1989), Leopold (2003), Petrides (1972), and Rushforth (1999). If an extensive tree inventory is available, this could inform the development of maximum DBH values. Ideally, DBH data could be pooled at a regional level (i.e., across municipalities). Maximum urban tree DBH values may not be immediately available; however, once developed, RDBH will provide quantifiable targets for tree size and distribution across the community. Additionally, it enables managers to determine whether urban trees are able to reach their genetic potential for a given species, which is largely dependent on the condition of the planting site and other factors.

Maintaining a diverse species mix (species diversity) is a critical way to promote a healthy and resilient urban forest (Santamour 1990). Maintaining species diversity is a function of the number of species present, as well as how those species are spatially distributed across the community. Therefore, this original criterion was further divided into two distinct criteria and key objectives: 1) species suitability, to establish a tree population suited to the urban and regional environment, and 2) species distribution, to establish a genetically diverse population of trees throughout the urban forest. Tree species suitability can be based on regionallyspecific guidelines, such as those provided in the Council of Tree and Landscape Appraisers' regional supplements, which take into account concerns such as adaptability to local climate, and management needs. In the absence of such guidelines, a municipality can develop its own species suitability index, based on local expert opinion. While Clark et al.'s (1997) performance indicators track only the scope of assessment and inventory technology, the current revision encourages urban forest managers to account for species diversity at a level of detail (i.e., neighborhood level) not available through aggregate tree inventory data, thereby making this criterion better suited to long-term strategic planning.

The present study differentiates between intensively managed parts of the urban forest and extensively managed woodlands - that is, areas where individual trees are managed under arboricultural techniques as opposed to areas that are managed en masse using techniques more closely related to silviculture. While these various components together form the urban forest, the authors feel that it is critical that the unique approaches to management required in each are clearly recognized in the development of inventories and management plans as well as in some aspects of the criteria and indicators.

Typically, the majority of trees in an urban forest are in private ownership, and municipal resources are used to support the relatively small component of the canopy on public land (e.g., street trees). Therefore, the condition of intensively managed, publicly owned trees-with the key objective of a detailed understanding of the condition and risk potential of all public trees-is an important new criterion that can be used to evaluate the success of forest management and support strategic planning.

In communities with significant natural areas, a similar criterion is suggested in addition to the previous-publicly owned natural areas, which are primarily extensively managed. A detailed understanding of the ecological functions and structures, as well as information about public use of these areas, represents a significantly more sophisticated articulation of practical management concerns to support strategic planning.

Finally, the use of native species on public or private land may represent an important objective for sustainable urban forest management. While Clark et al.'s (1997) criteria and performance indicators are still generally robust, the current study expands on the 
public policy aspect of native species establishment, and suggests that the degree of public policy support for native species use in intensively- and extensively managed areas is an important performance indicator. The importance of project-appropriate use of native species is also highlighted. Nonnative plantings may be more appropriate in circumstances where poor growing conditions or limited space could prevent any native species from reaching their full genetic potential, or may significantly limit their longevity. The issue of plant invasiveness similarly are considered as well. Optimal urban forest management will always account for projectspecific considerations in tree establishment activities. While invasive plants should generally be discouraged, in some scenarios (i.e., away from natural areas), even potentially invasive trees may be preferable to no trees at all. Conversely, in growing conditions in proximity to natural areas but where no noninvasive trees will likely thrive, it may be preferable to forego tree establishment entirely.

In addition to the new criteria proposed here, the study authors believe that these developments based upon Clark et al.'s (1997) original criteria and indicators for managing the urban forest vegetation resource provide a more robust foundation for strategic planning, by setting more easily quantifiable targets as indicators of success.

\section{The Community Framework}

In a truly sustainable urban forest, all members of a community must cooperate to share the responsibility for tree resource management. Clark et al. (1997) proposed seven criteria to assess the strength of the community framework for urban forest sustainability: 1) public agency cooperation, 2) involvement of large private and institutional landholders, 3) green industry cooperation, 4) neighborhood action, 5) citizen-municipality business interaction, 6) general awareness of trees as a community resource, and 7) regional cooperation. On the whole, the original criteria and indicators are highly applicable for urban foresters to evaluate the success of their forest management activities relative to the community framework. However, the study authors do suggest several changes, as described below and summarized in Appendix 2.

In terms of public agency cooperation, it is important to distinguish between types of municipal interdepartmental cooperation. Revised performance indicators, which range from "conflicting goals" among departments (as in Clark et al. 1997) to formal interdepartmental working teams on all municipal projects, distinguish between project-specific and organization-wide formal cooperation, and allow urban forest managers to track incremental progress in reform of administrative structures and procedures.

A frequent obstacle to community cooperation around sustainable urban forest management is a lack of awareness of trees as a community resource. Clark et al. (1997) suggest that an optimal indicator of success is a community that recognizes the environmental and economic contributions made by the urban forest. While the study authors agree, it is also suggested that the community must be aware of the numerous social benefits provided by tree cover, thereby broadening the potential extent of the total supportive political constituency - a worthy undertaking to ensure long-term sustainable urban forest management and public health.

\section{The Resource Management Approach}

The resource management approach set of criteria and indicators concerns not only physical resource management but also pub- lic and administrative perceptions of management itself. Clark et al. (1997) suggested nine criteria and key objectives for successful urban forest resource management: 1) citywide management plan, 2) citywide funding, 3) city staffing, 4) assessment tools, 5) protection of existing trees, 6) species and site selection, 7) standards for tree care, 8) citizen safety, and 9) recycling. In addition to several new criteria, the proposed changes to the original criteria and key objectives are to improve their application to strategic urban forest management and planning (Appendix 3).

Although the importance of a routinely-updated and comprehensive tree inventory is addressed in the original assessment tools criterion, there was no distinction made between a tree inventory and a canopy cover inventory. An optimal tree inventory provides complete data for the entire public tree resource (generally excluding natural areas) and a sample-based inventory of private trees. In combination with a GIS-referenced canopy cover inventory, based on aerial or satellite imagery, the optimal level of inventory data will allow for both micro and macro-level tree resource management and strategic planning.

Clark et al. (1997) suggested that optimal citywide management planning must cover both public and private property-urban trees make no distinction between land tenure, yet tenure may have significant effects upon the health of individual trees and the canopy as a whole. No major modification to this criterion are suggested, but the importance of strategic planning for all components of the urban forest through a comprehensive, multi-tiered plan with clearly defined vision and goals, stakeholder input, and built-in mechanisms for adaptive management, are emphasized. Similarly, no changes to the municipality-wide funding criterion are suggested, other than to emphasize the importance of long-term strategic budgeting that extends well beyond simple tree establishment.

The number of municipal employees involved in urban forest management is not a sufficient indicator of the adequacy of city staffing. Furthermore, the optimal number of urban forestry personnel will vary among communities, making staffing targets an inappropriate benchmark. A better criterion would address the training, skill, and experience of the staff. It is suggested that a sustainable and optimally managed urban forest requires a broader range of skills and experience than can be provided by arborists or other professional tree care staff alone. Therefore, the importance of a multidisciplinary management team entrenched within a dedicated municipal forestry unit are highlighted. Such a team would optimally combine the tree care skills of arborists with the planning, modeling, and ecological background of professional foresters and ecologists to develop and implement successful strategic management plans.

It is recognized that species and site selection is an important consideration in tree establishment, but the Clark et al. (1997) key objective and indicators for this criterion make little provision for integrated establishment planning to achieve strategic goals and the community vision. Therefore, the study authors propose this criterion be modified to highlight tree establishment planning and implementation, with the objective of renewing and expanding the urban forest through a comprehensive tree establishment program driven by increasing canopy cover, species diversity, species distribution and maximizing tree growth and longevity. These proposed indicators make explicit the connections between the data source supporting establishment planning (tree inventory) and desired biological outcomes on a site and aggregate (canopy cover) level. 
Also proposed here is a new criterion of tree habitat suitability. The suitability of the habitat will not only be determined by the growing environment but also by the desired functions trees should perform at any given site. The key objective for this criterion is that municipal tree establishment programs ensure that all publicly owned trees are planted on sites where the above- and belowground conditions will maximize current and future benefits. In an optimal situation, all planting sites will be assessed for soil volume and quality, and provisions for matching species with their sites or amending sites to suit the desired tree species will be implemented.

Although tree establishment is an effective part of increasing the extent of the urban forest, the adherence to professional standards for tree care of existing trees is equally important, if not more so. Following the proposal of two new vegetation resource criteria concerning public and private trees, it is recommended that the original standards for tree care criterion be divided to reflect the different management requirements of intensively- and extensively managed trees. Maintenance of publicly owned, intensively managed trees on a cyclical basis will ensure the maximization of benefit provision and tree longevity over time, reducing future costs and potential liability from tree failure. Management planning and implementation in extensively managed natural areas is an analogous criterion for natural areas, and optimal implementation would ensure the protection and enhancement of natural structures and functions. These two new criteria, adapted from Clark et al.'s (1997) original tree protection criterion, reflect the importance of integrated policy mechanisms, while facilitating strategic planning by distinguishing between public, intensively managed resources and more extensively managed natural areas.

As a greater share of urban forest benefits is derived from large-stature and well-established trees, the protection of existing trees is a key criterion for successful management. No major modifications are recommended to either the criterion or the indicators, but the study authors do stress the importance of consistent enforcement of tree protection policies, coupled with effective deterrents to prevent offenses from first occurring.

Finally, it is proposed that the criterion of citizen safety, supported by relative indicators in Clark et al. (1997), be modified to include indicators in absolute terms in a program of comprehensive tree risk management. To move beyond the "low" performance level, this criterion requires the presence of at least a sample-based inventory with general tree risk information, highlighting the importance of strategic management based on sound data concerning the urban forest resource.

\section{CONCLUSION}

In this paper, the reasons canopy cover alone cannot provide an accurate representation of the structure, health, and function of an urban forest were discussed, along with why overly ambitious canopy cover targets, unless accompanied by more comprehensive criteria, may in fact be detrimental to urban forest sustainability. More importantly, however, is the presentation of an updated framework of criteria and indicators. Building upon the foundation laid by Clark et al. (1997), these criteria and indicators will help managers, policy makers, and other stakeholders to move beyond thinking about their urban forests as two-dimensional entities described solely by canopy cover.

Assessing a community's relative performance in each of the twenty-five proposed criteria and indicators may seem like a daunt- ing challenge at first. Although most criteria can be easily assessed with minimal analysis, several C\&I depend upon somewhat more sophisticated analyses or detailed information. However, communities that may lack the resources to conduct such assessments should not overlook the importance of these criteria; instead, they should consider any current shortfalls as opportunities to set future strategic objectives and management or budget priorities.

Urban forest managers must also recognize the flexible nature of many of the proposed C\&I. Even though several performance indicators are based on discrete thresholds (for example, see relative canopy cover), others are open to more subjective interpretation. For instance, "adequate" funding or staffing to optimize urban forest management will differ greatly among communities; a metropolis with more than one million residents will surely define adequacy far differently than a rural village. The strength of the approach outlined in this paper lies in the fact that urban forest managers in both types of communities, regardless of any other factors, can use the same set of criteria and indicators to assess and track their progress toward true urban forest sustainability. Communities, and particularly their politicians and senior management staff, need not fear scoring in the lower range of assessment; lower scores simply highlight opportunities for future improvements.

While criteria and indicators are useful tools for evaluating existing management practices, the use of C\&I in this capacity alone does not guarantee successful sustainable urban forest management. An adaptive plan or framework reflecting a community's commitment, vision, and goals, and enabling strong links between these and daily on-the-ground operations, is equally important.

The updated criteria and indicators presented here have been successfully incorporated into a long-term strategic urban forest management plan for the Canadian municipalities of Oakville (Urban Forest Innovations and Kenney 2008), Burlington (2010) and Ajax, Ontario (in press), and are being used as a model for the development of similar plans in other municipalities.

The applicability of criteria and indicators as a powerful tool for urban forest management was recognized more than a decade ago, yet policymakers and managers continue to overlook their potential to ensure the long-term provision of urban forest benefits in any size of community. Contemporary urban forest professionals cannot only monitor and adjust policies determined by others. Ideally, they will be leaders in decision-making processes, and at a minimum be active participants in urban forest management planning. The set of criteria and indicators for urban forest sustainability presented here can aid in the planning process by guiding an analysis of strengths, weaknesses, opportunities, and threats. They can also serve as a nucleus, around which a long-term strategic urban forest management plan can be designed, and against which a series of milestones progress through the implementation of the plan, which can be measured. Because urban forest management and planning is complex, these $\mathrm{C} \& \mathrm{I}$ can also serve as a concise yet comprehensive communications tool for managers charged with explaining their challenges to politicians, other professionals, and the general public.

The paper by Clark et al. (1997) represents the seminal work for the growing dialogue about sustainable urban forest management. The authors' framework of key objectives, criteria, and performance-based indicators for urban forest management success recognized the dynamic and multi-faceted nature of urban forests, and provided a promising tool for the development of citywide urban forest management planning. However, years later, the relative success or failure of urban forest management in communi- 
ties across North America is still far too often measured by canopy cover alone. It is hoped that the expanded and updated criteria and indicators presented here provide a more comprehensive, strategic, and sustainable context for urban forest management planning.

\section{LITERATURE CITED}

American Forests. 2009. Setting urban tree canopy goals. Retrieved May 1, 2009. <http://www.americanforests.org/resources/urbanforests/ treedeficit.php>

Canadian Council of Forest Ministers. 2006. Criteria and indicators of sustainable forest management in Canada: National status 2005. Natural Resources Canada, Canadian Forest Service, Ottawa.

Carreiro, M.M., Y-C. Song, and J. Wu. 2007. Ecology, planning and management of urban forests: International perspectives. Springer, New York.

City of Burlington. 2010. Urban Forest Management Plan, 2011-2030. Retrieved April 25, 2011. <http://cms.burlington.ca/Page5824.aspx>

Clark, J.R, N.P. Matheny, G. Cross, and V. Wake. 1997. A model of urban forest sustainability. Journal of Arboriculture 21:17-30.

Clark, J.R., and N.P. Matheny. 1998. A model of urban forest sustainability: Applications to Cities in the United States. Journal of Arboriculture 24:112-120.

Dwyer, J.F., H.W. Schroeder, and P.H. Gobster. 1991. The significance of urban trees and forests: toward a deeper understanding of values. Journal of Arboriculture 17:276-284.

Farrar, J.A. 1995. Trees in Canada. Fitzhenry and Whiteside, Markham.

Humble, L.M., and E.A. Allen. 2004. Alien Invaders: Non-indigenous species in urban forests. In: W.A. Kenney (Ed.) Proceedings of the 6th Canadian Urban Forest Conference, October 19-23, 2004, Kelowna, British Columbia.

Kenney, W.A. 2004 (Ed.). Proceedings of the 6th Canadian Urban Forest Conference, October 19-23, 2004, Kelowna, British Columbia.

Kenney, W.A. 2008. Potential Leaf Area Index Analyses for the City of Toronto's urban forest. In: M.M. Carreiro, Y-C. Song, and J. Wu. 2007 (Eds.). Ecology, planning and management of urban forests: International perspectives. Springer, New York: 336-345.

Kershaw, L.J. 2001. Trees of Ontario. Lone Pine Publishing, Edmonton.

Kirnbauer, M.C., W.A. Kenney, C.J. Churchill, and B.W. Baetz, 2009. A prototype decision support system for sustainable urban tree planting programs. Urban Forestry \& Urban Greening 8:3-19.

Lauriault, J. 1989. Identification guide to the trees of Canada. Fitzhenry and Whiteside. Markham.

Leopold, D.J. 2003. Trees of New York State: Native and naturalised. Syracuse University Press, Syracuse, NY.

McPherson, G., J.R. Simpson, P.J. Peper, S.E. Maco, and Q. Xiao. 2005. Municipal Forest Benefits and Costs in Five US Cities. Journal of Forestry 103:411-416.

Monear, J., and I. Hanou. 2010. Roadmap to tree planning and planting. Presentation at ISA 2010 Annual Conference, Building the Roots of Arboriculture. July 28, 2010. Chicago, IL

Nowak, D.J., M. Kuroda, and D.E. Crane. 2004. Tree morality rates and tree population projections in Baltimore, Maryland, USA. Urban Forestry \& Urban Greening 2:139-147.

Petrides, G.A. 1972. A Field guide to trees and shrubs: Second edition. Houghton Mifflin \& Co, Boston.

Rushforth, K. 1999. Trees of Britain and Europe. Harper Collins, London.

Sanders, R.A. 1984. Some determinants of urban forest structure. Urban Ecology 8:13-27.

Santamour, F.S. 1990. Trees for urban planning: Diversity, uniformity, and common sense. In: Trees for the nineties: Landscape tree selec- tion, testing, evaluation and introduction. Proceedings of the seventh conference of The Metropolitan Tree Improvement Alliance (METRIA), June 11-12, 1990, The Morton Arboretum, Lisle, Illinois.

Urban Forest Innovations, and W.A. Kenney. 2008. Urban forest strategic management plan for the Town of Oakville 2008-2027. Retrieved May 1, 2009. <http://www.oakville.ca/Media_Files/ forestry/2008UFSMPappendices.pdf>

USDA Forest Service Northern Research Station Urban Tree Canopy Assessment. Retrieved March 22, 2010. <http://www.nrs.fs.fed.us/ urban/utc/>

Wua, C., Q. Xiaoa, and E.G. McPherson. 2008. A method for locating potential tree-planting sites in urban areas: A case study of Los Angeles, USA. Urban Forestry \& Urban Greening 7:65-76.

\section{W. Andy Kenney (corresponding author)}

University of Toronto - Faculty of Forestry

33 Willcocks Street

Toronto, Ontario M5S $3 B 3$

Canada

a.kenney@utoronto.ca

Philip J.E. van Wassenaer

Urban Forest Innovations

1248 Minnewaska Trail

Mississauga, Ontario L5G 3S5

Canada

Alexander L. Satel

Urban Forest Innovations

1248 Minnewaska Trail

Mississauga, Ontario L5G $3 S 5$

Canada

Résumé. Le succès en gestion de la forêt urbaine est fréquemmen évalué en fonction de l'atteinte de cibles de couverture absolue en végétation. Cette vue bidimensionnelle de la forêt urbaine ne donne pas une évaluation conséquente de la régie d'une telle forêt au sein d'une communauté ni ne tient compte de la superficie potentielle pour soutenir ce couvert forestier. Un ensemble détaillé de critères de base de performance et d'indicateurs sont décrits concernant les ressources en végétation de la communauté, le cadre de la communauté et l'approche de gestion de la ressource. Cet ensemble de variables de mesures fournit un outil plus efficace pour évaluer le succès en gestion de la forêt urbaine ainsi que pour la planification de la gestion stratégique.

Zusammenfassung. Der Erfolg des urbanen Forstmanagements wird gelegentlich durch das Erzielen absoluter Kronenbedeckung bestimmt. Diese zweidimensionale Sicht der urbanen Forste liefert keine umfassende Wertschätzung von den Leistungen urbaner Forste in einer Kommune und kann nicht herangezogen werden für die Bewertung des Potentials einer Fläche, dort einen Wald zu etablieren. Eine umfassende Aufstellung leistungsbasierter Kriterien und Indikatoren betreffend der vegetativen Ressourcen, kommunaler Rahmenbedingungen und Ressourcenmanagement wird hier beschrieben. Dieses breitangelegte Set liefert ein weiteres nützliches Werkzeug für die Bewertung des Erfolges urbanen Forstmanagements und der strategischen Management-Planung.

Resumen. El éxito en el manejo de los bosques urbanos es frecuentemente predicho con base en datos de cobertura. Esta vista bidimensional de un bosque urbano no proporciona una valoración comprensiva en una comunidad y no responde por un área potencial para soportar un dosel forestal. Se describe una serie de criterios e indicadores concernientes a los recursos de vegetación de la comunidad. Este paquete de medidas proporciona una herramienta útil para la evaluación del manejo forestal y las estrategias de manejo. 


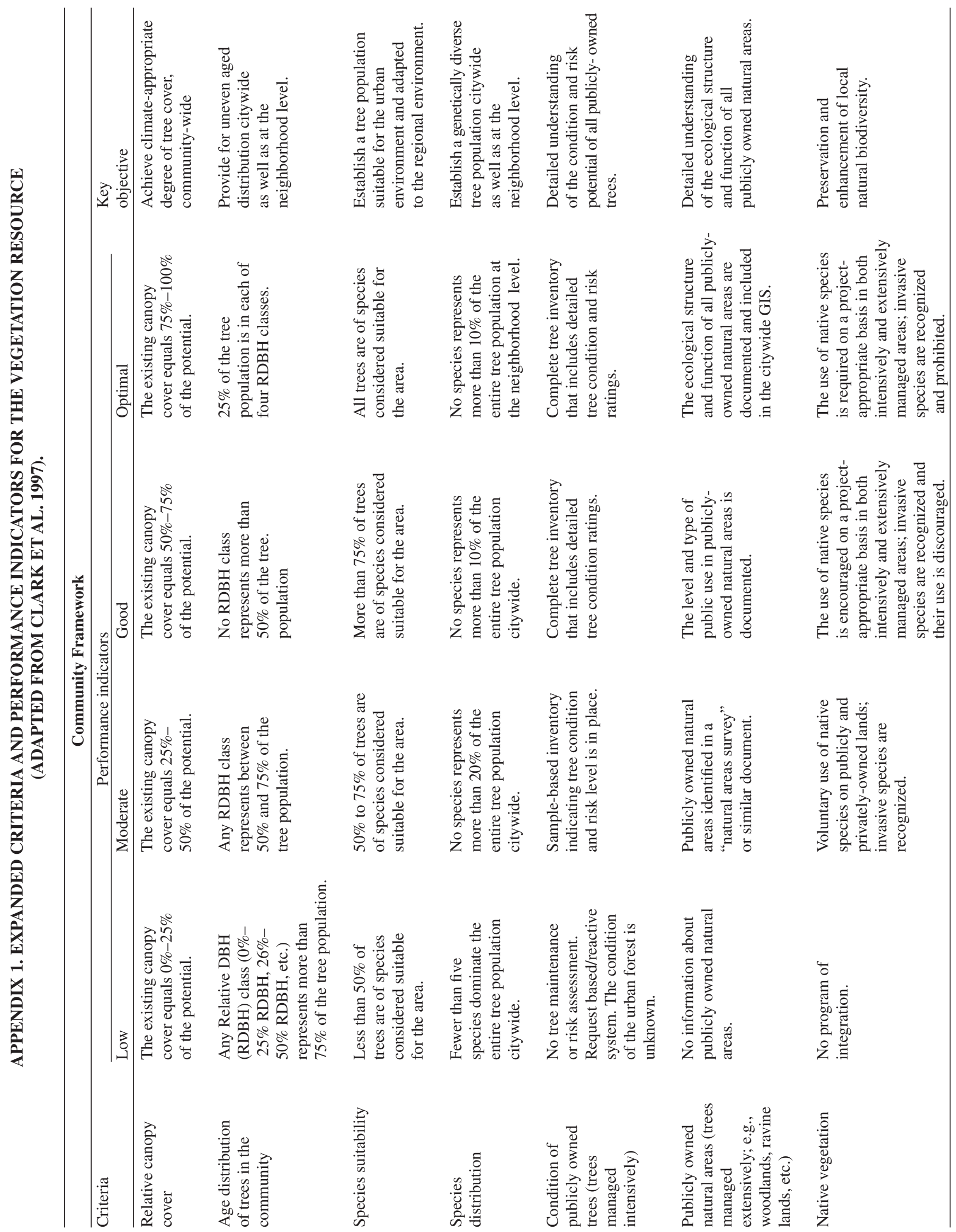

(02011 International Society of Arboriculture 


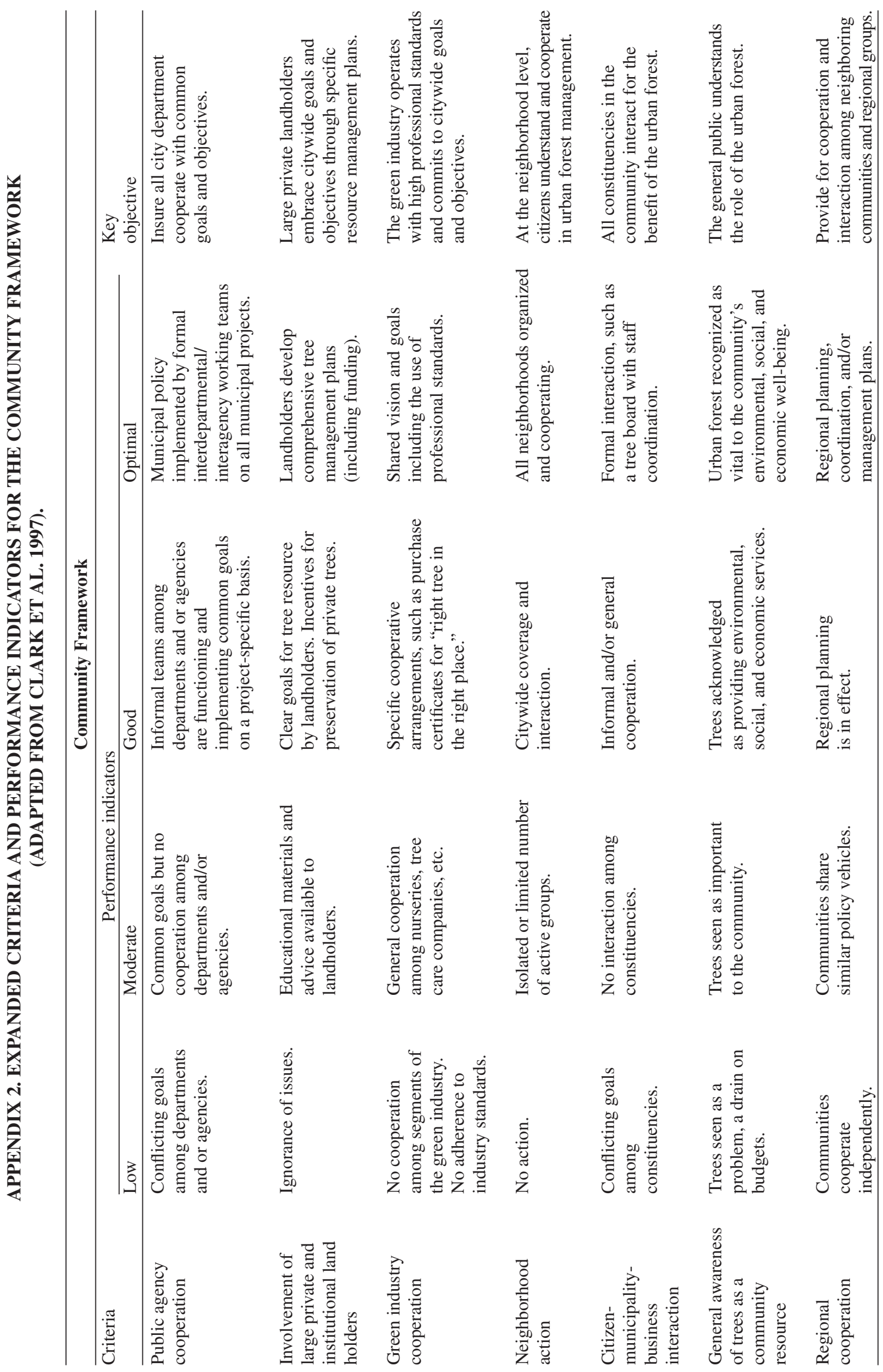




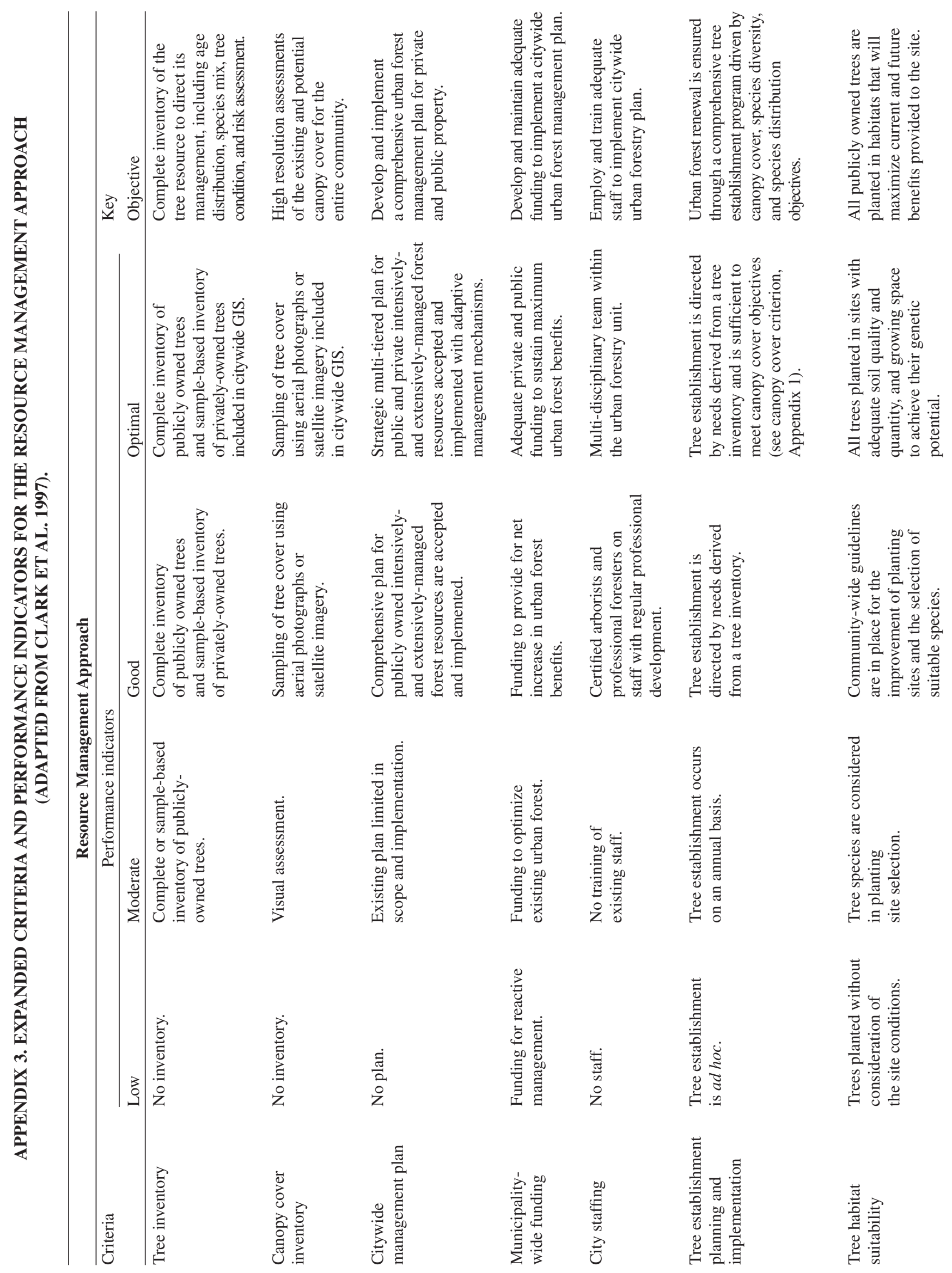

(O2011 International Society of Arboriculture 


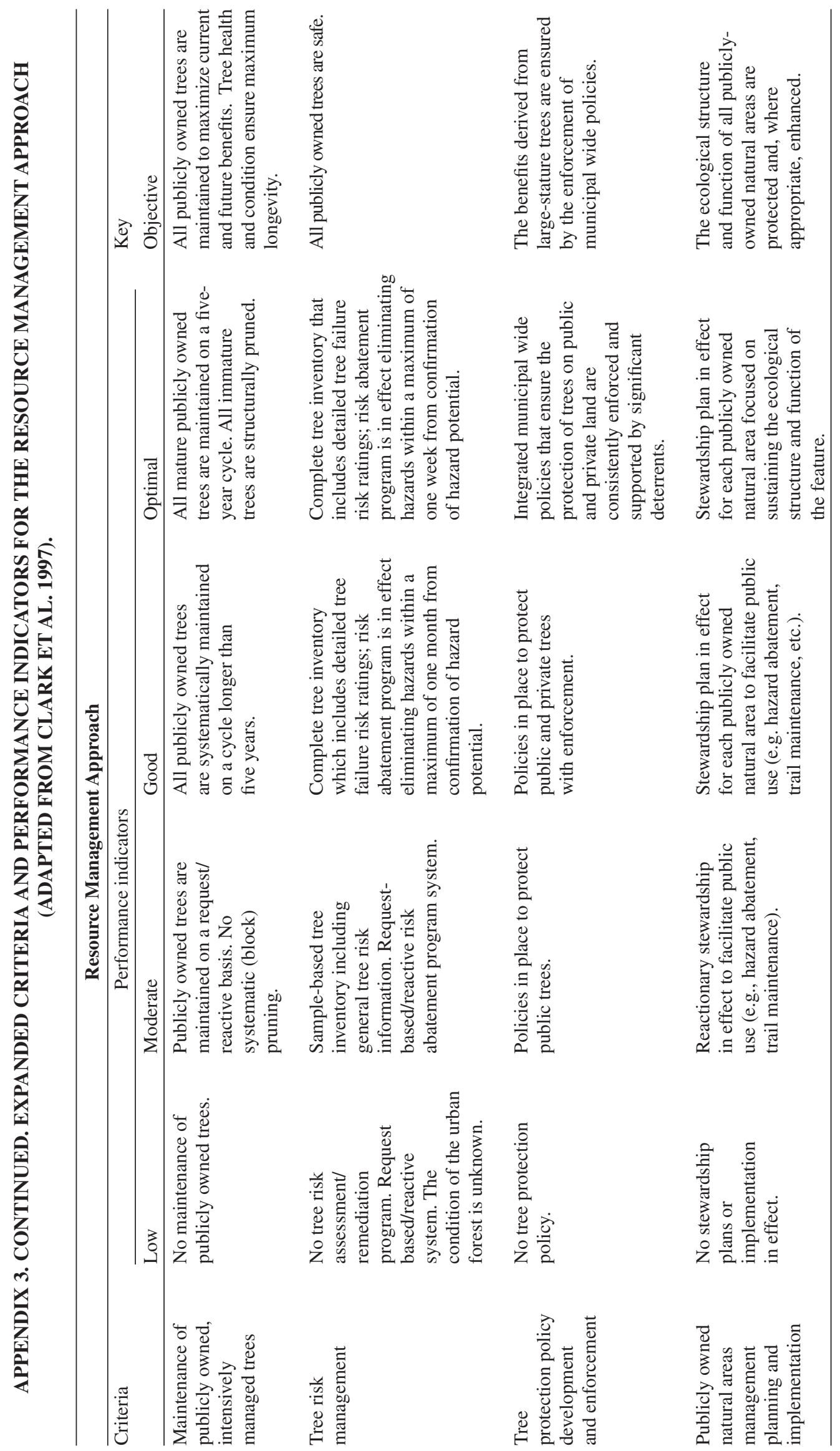

